\title{
1. Consumer spending on spectator sports, physical activity, and gambling: evidence from Canada
}

\author{
Brad R. Humphreys, Jane E. Ruseski and \\ Jie Yang*
}

\subsection{INTRODUCTION}

Recent developments in North America underscore the importance of understanding the economic relationship between consumer spending on leisure activities, gambling, and exercise or participation in physical activity. Both labor force participation and participation rates in physical activity continue to decline worldwide, suggesting that consumers spend more time pursuing other leisure activities. Legal opportunities for gambling have expanded, and sports betting opportunities also appear to be expanding. In Canada, the federal government has considered amending the Criminal Code to legalize betting on individual sporting events. In the US, states have pushed for legalized sports betting. The outcome in both countries is still undecided. This chapter analyzes the relationship between spending on sports betting and other leisure-related consumer spending to understand how increasing access to sports betting opportunities might affect other types of spending.

We use detailed household-level data from the Survey of Household Spending (SHS), a large-scale annual Canadian survey of consumer economic activity to estimate an Almost Ideal Demand System (AIDS) for these three consumer goods and services. AIDS models have been used extensively in recent research to analyze consumer spending, including spending on gasoline and consumer transportation (Chang and Serletis, 2013), consumer travel (Mangion et al., 2012), consumer non-durables (Blow et al., 2012), food (Koohi-Kamali, 2013), and residential energy (Guta, 2012; Gebreegziabher et al., 2012).

Flexible functional form demand models like AIDS allow for the estimation of own and cross price elasticities for consumer goods and services that can be interpreted as approximations to general consumer choice 
models. These models generate estimates consistent with aggregation across households, which make them ideal for use with consumer expenditure survey data like the SHS data analyzed here.

We find that household spending on sports betting and attendance at spectator sports are complements, but household spending on sports betting and spending on leisure time exercise are substitutes, based on estimates from an Almost Ideal Demand System using spending data from 145,560 Canadian households over the period 1997-2009. Since household spending on sports betting and spending on attendance at sporting events are complements, professional sports leagues in North America have little reason to worry that the expansion of legal sports betting opportunities will reduce attendance-based revenues; instead, our evidence suggests that expanding legal sports betting may increase attendance at live sporting events, generating larger revenues for sports teams and leagues.

However, the evidence that consumer spending on sports betting and spending on exercise and physical activity are substitutes suggests that increasing access to legal sports betting may have unintended consequences, if the reduced household spending on physical activity and exercise reflects reduced participation in physical activity, since reduced participation in physical activity has been linked to adverse health outcomes (Humphreys et al., 2014).

\subsection{GAMBLING, EXERCISE, AND ATTENDANCE}

Gambling, including sports betting, is a highly regulated economic activity in Canada. The other two categories of consumer spending analyzed here, spending on live attendance at sporting events and spending on leisure time physical activity, are not regulated. Professional sports, and Division I intercollegiate athletics in North America are produced by monopoly sports leagues. Access to sports betting depends on both government regulations and the willingness of certain individuals to violate these regulations. Simmons (2007) analyzed factors influencing gambling regulations. He identified a tension between consumers, who view gambling as entertainment or a financial transaction, and governments, who view state sponsored monopoly gambling as a source of revenues. Significant illegal sports betting operations exist in many countries, particularly the US. Strumpf (2003) documented the number and nature of the extensive US illegal sports betting operations.

Sauer (2001) analyzed the regulation and availability of legal gambling using a public choice model in which governments set regulations in response to lobbying by interest groups, including pro-gambling 
consumers whose welfare rises with gambling access and falls with gambling regulation, and an anti-gambling lobbying group who wants to restrict gambling access. The anti-gambling lobbying group includes individuals and organizations like churches that disapprove of gambling for different reasons. In the case of sports betting, the anti-gambling group may also contain professional and amateur sports organizations like the NFL, NBA, NHL and NCAA. The gambling regulations predicted by this model depend on the relative lobbying efforts made by the two groups.

Forrest and Simmons (2003) reviewed the economic and public policy context for sports betting. They highlighted the recent and rapid growth in sports betting worldwide and discussed the implications for revenue generation for government and sports organizations. They identified a number of negative aspects of sports betting, including incentives for corruption. They also emphasized the symbiotic nature of the relationship between sport and sports betting, and pointed out the importance of complementarities between watching sport and sports betting as well as the tensions generated by this relationship. The importance of complementarities in consumption drives demand for sports betting and puts pressure on governments to expand sports betting opportunities, while the corruptive factors fuel the desires of anti-sports gambling groups and leads to increased pressure to restrict sports betting opportunities.

Even though gambling, and sports betting, is highly regulated in both Canada and the United States, government regulators are currently debating policy changes that would significantly increase access to legal sports betting in both countries. In Canada, the Criminal Code currently prohibits single-event sports betting but allows parlay-style betting on two or more sporting events. However, Bill C-290 ("an Act to amend the Criminal Code") that would legalize single-event sports betting was passed unanimously by the Canadian House of Commons in December 2012 and is currently being debated by the Senate. The governments of eight Canadian provinces have formally supported passage of the bill. The National Hockey League (NHL) has vocally opposed the bill, claiming that legal single-event sports betting will lead to reduced revenues and increase the likelihood that gamblers will try to fix game outcomes. During legislative hearings on the bill, experts testified that Canadians currently spend between $\$ 10$ and $\$ 40$ billion annually betting on single sporting events with illegal bookmakers and about $\$ 4$ billion annually betting on single sporting events with on-line offshore bookmakers that are not regulated by Canadian provinces.

In the US, the State of New Jersey passed a law legalizing single-event 
sports betting in 2012 following a successful 2011 referendum on the issue. Single-event sports betting is currently legal at casinos in Las Vegas, and, under the federal Professional and Amateur Sports Protection Act (PASPA) of 1993, sports betting can be legalized in four states (Nevada, Oregon, Delaware and Montana). The four major professional sports leagues operating in the US, the National Football League (NFL), Major League Baseball (MLB), the National Basketball Association (NBA) and the National Hockey League (NHL) along with the National Collegiate Athletic Association (NCAA) challenged New Jersey's legalization of sports betting immediately after the law was passed and obtained an injunction against the implementation of the law. The sports leagues claimed that increased access to sports betting would damage the public perception of professional sports, leading to long-term and irreparable economic damage in the form of lost revenues.

Little evidence about the relationship between legal sports betting and professional sports leagues currently exists. Forrest and Pérez (2011) show that the presence of high-profile football matches on the betting coupon increases the volume of bets placed in La Quiniela, a football pool betting game operated by the Spanish National Lottery. García and Rodríguez (2007) and García et al. (2008) reported evidence of important complementarities between watching or following sporting events and sports betting in La Quiniela in Spain. No formal evidence of such complementarities exists in other countries.

Canadians have access to legal sports betting as part of a group of government-sanctioned lottery games. These games have different names in different parts of Canada. In Quebec, the lottery-based sports betting game is called Pari Sportif; in Ontario and Atlantic Canada this game is called Pro-Line; in Manitoba, Saskatchewan and Alberta it is called Sports Select; in British Columbia it is called Sports Action. In western Canada, consumers also have access to a lottery-based game based on point spreads. All of these lottery-based sports betting games are available at lottery outlets. In some provinces, sports betting and other lottery tickets can be purchased on the internet. In 2011, total sales of government sponsored lottery products in Canada were $\$ 4.76$ billion dollars. Canadians have easy access to lottery outlets. About $\$ 237$ million of these sales came from sports betting games, just over 5 per cent of total sales. In 2011 there were 30,090 lottery outlets in Canada, roughly one lottery outlet for every 900 persons age 18 and older.

These Canadian lottery-based sports betting games, except Point Spread, are based on fixed odds bets on game outcomes and total points scored in professional and amateur sports leagues, including games in the major North American sports leagues and US college football and basketball 
games. These games feature parlay-style betting where gamblers must pick the outcome of between two and 12 games.

Winnings in Canadian sports betting games are not pari-mutuel; lottery corporations make profits based on over-round, the amount by which the win probabilities implied by the fixed betting odds offered on specific outcomes exceed 100. The over-round on Canadian sports betting games varies with the number of events selected in the lottery ticket. The minimum over-round is 160 per cent and it can exceed 300 per cent depending on the bets placed. Winnings are capped at $\$ 2,000,000$ per card no matter how large the odds on the selected events or the number of games included in the parlay wager.

Given that Canadians currently have access to a form of sports betting offered at lottery outlets throughout the country, data on household spending on government operated lotteries and other related consumer goods can provide new insights into the relationship between sports betting and other sectors of the economy like professional sports. In the following sections, we describe the data source, empirical methods, and results of this analysis.

\subsection{DATA DESCRIPTION}

The data come from the SHS conducted by Statistics Canada. We used the SHS confidential micro data from 1997 to 2009, which includes detailed information about household expenditure. In particular, the SHS contains information about household expenditure on attendance at live sporting events, physical activity/physical fitness and the government-run lottery as well as detailed household demographic characteristics.

The SHS has been conducted in the ten Canadian provinces annually since 1997 and in the three Canadian territories biannually since 1999 . The coverage of the population is about 98 per cent in the provinces and 90 per cent in the territories. However, there was a drop in coverage in Nunavut in 2005 (68.3 per cent) due to changes in sampling methods. The SHS contained about 20,000 eligible households each year before 2007 . However, the sample size was reduced by nearly 30 per cent after 2008 due to Statistics Canada budget cuts. The response rates for the SHS have been about 66 per cent, varying from 63.4 per cent in 2008 to 76.2 per cent in 2001.

In the SHS, detailed information about household expenditure for the reference (calendar) year is collected during the personal interview. A paper questionnaire was used before 2006 and replaced by computer assisted personal interviews, starting in 2006. Also starting in 2006, the 
SHS collected information about dwelling characteristics and household equipment at the time of the interview instead of at the end of the reference year. Another important change since 2006 was that there was no distinction between "part-year" and "full-year" household members. Data were collected for every household member as of the time of the interview.

The SHS sample uses stratification and multi-stage selection from the Labour Force Survey (LFS) sampling frame. From 1997 to 2003, SHS used 1991 Census geography and population counts; from 2004, SHS used 2001 Census geography and population counts after the major sample redesign of the LFS. SHS also used Census of Population and T4 data from the Canada Revenue Agency to adjust the survey weights. For comparisons over these years, data from the 1997-2003 SHS were also re-weighted using the new weighting methodology. However, since the SHS employed a complex survey design and also considered uneven respondent selection probabilities, estimation and variance calculations using the weighted sample over these years may be problematic for certain subgroups or variables.

Extra questions were included in several survey years, but none of these relate to this topic. The final data set contains all SHS households reporting positive total expenditure on attendance at live sporting events, physical activity and exercise, and government-run lotteries (which includes sports betting) from the SHS confidential micro data files. The sample contains 145,560 observations including data from more than 40,000 Canadian households from 1997-2009. Due to the nature of confidential data, we cannot determine whether the same households participated in the surveys in multiple years. Thus, we assume that all 145,560 observations were from different households. Summary statistics are shown on Table 1.1. Note that we cannot report the maximum and minimum values in the sample due to the Statistics Canada confidentiality policy. Instead, we report the values at the 0.02 per cent percentile and 99.98 per cent, which can almost be regarded as the minimum and maximum values.

The reported Real Expenditure on Table 1.1 is the total real annual household expenditure for admissions to live sporting events, total fees (including membership and single usage fees) and dues for sports activities, sports and recreation facilities, and health clubs, and spending on government-run lotteries. It varies from about $\$ 1$ to over $\$ 15,000$. Table 1.1 also shows the shares of total expenditures for those three spending categories. On average, the share of spending on spectator sports event attendance is the smallest, only about 10 per cent of spending. Spending on government-run lotteries and sports betting is the largest, accounting for over one-half of this spending. For each of the three goods and services, there were always some households that spent nothing on one or two 
Table 1.1 Summary statistics

\begin{tabular}{|c|c|c|c|c|}
\hline Variable & Mean & Std. dev. & $\begin{array}{c}0.02 \mathrm{nd} \\
\text { percentile }\end{array}$ & $\begin{array}{c}99.98 \text { th } \\
\text { percentile }\end{array}$ \\
\hline $\begin{array}{l}\text { Budget share, admissions to live } \\
\text { sports events }\end{array}$ & 0.101 & 0.237 & 0 & 1 \\
\hline $\begin{array}{l}\text { Budget share, expenditure on } \\
\text { physical activities }\end{array}$ & 0.364 & 0.411 & 0 & 1 \\
\hline $\begin{array}{l}\text { Budget share, expenditure on } \\
\text { government-run lottery }\end{array}$ & 0.535 & 0.435 & 0 & 1 \\
\hline Real Expenditure & 518 & 847 & 1.02 & 15,734 \\
\hline Reference Person Age & 48.3 & 15.5 & 17 & 94 \\
\hline Real Household Income (000) & 62.41 & 79.38 & 0 & $1,163.52$ \\
\hline Urban Household & 0.786 & - & 0 & 1 \\
\hline \multicolumn{5}{|l|}{ Housing tenure } \\
\hline Homeowner without mortgage & 0.334 & - & 0 & 1 \\
\hline Homeowner with mortgage & 0.360 & - & 0 & 1 \\
\hline Tenants - regular & 0.266 & - & 0 & 1 \\
\hline Tenants - rent-free & 0.009 & - & 0 & 1 \\
\hline Mixed tenure & 0.031 & - & 0 & 1 \\
\hline \multicolumn{5}{|l|}{ Major income source } \\
\hline No income & 0.001 & - & 0 & 1 \\
\hline Paid employment & 0.664 & - & 0 & 1 \\
\hline Self-employment & 0.065 & - & 0 & 1 \\
\hline Investment income & 0.014 & - & 0 & 1 \\
\hline Government transfer payments & 0.185 & - & 0 & 1 \\
\hline Miscellaneous income & 0.071 & - & 0 & 1 \\
\hline \multicolumn{5}{|l|}{ Household type } \\
\hline Single female & 0.110 & - & 0 & 1 \\
\hline Single male & 0.097 & - & 0 & 1 \\
\hline Couple only & 0.276 & - & 0 & 1 \\
\hline Couple with children & 0.379 & - & 0 & 1 \\
\hline Single mother & 0.060 & - & 0 & 1 \\
\hline Single father & 0.014 & - & 0 & 1 \\
\hline Other & 0.063 & - & 0 & 1 \\
\hline \multicolumn{5}{|l|}{ Household employment status } \\
\hline $\begin{array}{l}\text { Reference person and spouse } \\
\text { unemployed }\end{array}$ & 0.213 & - & 0 & 1 \\
\hline At least one has a part-time job & 0.461 & - & 0 & 1 \\
\hline Both have full-time jobs & 0.325 & - & 0 & 1 \\
\hline
\end{tabular}


of these ( share $=0$ ) or only spent money on one of the goods and services ( share $=1)$.

Real Household Income is the household's total annual income before taxes in the reference year. The average income in our sample is just above $\$ 62,000$; the top-earning households in the sample earned over \$1 million. Reference Person Age is the age of the reference person in the reference year. For one-person or single-parent households, the household income is mainly earned by the reference person. From an economic point of view the age of the reference person can be regarded as the age of the household. For couples, the age of the spouse of the reference person is highly correlated with the age of the reference person. As a matter of fact, the ages of couples are usually very close to each other. Hence we can use the reference person's age as the age of the household.

The rest of the variables on Table 1.1 are all indicator variables. Urban identifies whether the household is in an urban area. Most households (78.6 per cent) in our sample lived in urban areas. The definition of urban area follows the census definition: "minimum population concentrations of 1,000 and a population density of at least 400 per square kilometre." The other 21 variables are categorized in four groups: housing tenure, major income source, household type and household employment status.

The SHS identifies five types of housing tenure. The shares of households with and without a mortgage are both about one-third of the sample. Regular renters account for a bit more than one-quarter of the sample. Also, nearly 1 per cent are special tenants who don't pay rent. Roughly 3 per cent of households are in the mixed tenure group. They both owned and rented their dwellings in the reference year. Major household income sources are divided into six groups. Over two-thirds of the households reported income from paid employment as the major source of income. Less than 20 per cent of households depended on government transfer payments as the major source of income. A significant part of this subgroup was retired.

Since the SHS reflects household spending, accounting for household type is important when analyzing expenditure. The SHS identifies four basic household types: one-person households, couples, single-parent households, and other household types. We further broke households down into seven types: single female households, single male households, couples-only households, couples with children and/or other persons, single mothers, single fathers and other households. The rationale here was to separately identify the impacts of gender and the presence of children on expenditure patterns. In the fourth household type, couples with children and/or other person(s) living in the household, other persons refer to children whose marital status is not "single, never-married", relatives by birth or marriage, and unrelated persons. The definition is complex, 
but basically most households in this type are just couples with children. About 20 per cent of the sample is one-person households. Single females and single males constitute similar shares of the sample. Couples accounted for almost two-thirds of the households in the sample. Couples with children were more common than couples without children. Six per cent of the households in the sample are single mother households, about four times the share of single father households.

Household employment status consists of three variables identifying three different labor market outcomes: (1) both the reference person and the spouse have no job (if reference person had a married or common law spouse); (2) at least one of the couple has a part time job; and (3) both of the couple have full time jobs. The largest group in the sample is type (2) households. In 46.1 per cent of the sample households, at least one person was working during the reference year, but both members of the couple did not have full time jobs. Also a little more than 20 per cent of households had no jobs at all.

\subsection{EMPIRICAL METHODS}

Deaton and Muellbauer (1980) developed the AIDS model, which represents "an arbitrary first-order approximation to any demand system" (Deaton and Muellbauer (1980)). This model satisfies all standard axioms of choice and aggregates perfectly over consumers. Its simple functional form makes it relatively easy to estimate.

Expressed in budget shares, the AIDS demand function is:

$$
w_{i}=\alpha_{i}+\sum_{j} \gamma_{i j} \log p_{j}+\beta_{i} \log \left(\frac{m}{a(p)}\right)
$$

where $w_{i}$ is the share of the household budget spent on good or service $i, p_{i}$ is the price of good or service $i$ and the price index $a(p)$ is defined by:

$$
\log a(p)=\alpha_{0}+\sum_{k} \alpha_{k} \log p_{k}+\frac{1}{2} \sum_{j} \sum_{k} \gamma_{k j} \log p_{k} \log p_{j}
$$

We used the Consumer Price Index (CPI) component for spectator entertainment (excluding cablevision and satellite services) as the price of attending sports events, and the component for use of recreational facilities and services as the price of physical activity. Since the price of a ticket in the sports lottery was constant over time, $\$ 1$ or $\$ 2$ per ticket, we used the inverse of the CPI to approximate this price. There are three restrictions on the parameters of Equation (1.1), which ensure the demand function system satisfies: (1) the sum of the share functions equals $1\left(\sum w_{i}=1\right)$; 
(2) each share function is homogeneous of degree zero in prices and (3) Slutsky symmetry.

$$
\begin{gathered}
\sum_{i=1}^{n} \alpha_{i}=1, \sum_{i=1}^{n} \beta_{i j}=0, \sum_{i=1}^{n} \gamma_{i j}=0 \\
\sum_{j} \gamma_{i j}=0 \\
\gamma_{i j}=\gamma_{j i}
\end{gathered}
$$

The effect of changes in prices on the budget shares is reflected in the parameters $\gamma_{i j}$ and changes in expenditure $(m)$ reflected in the parameters $\beta_{i}$. Goods with an increasing expenditure when income increases, luxury goods, have a positive $\beta_{i}$ and goods with a decreasing budget share as income increases, necessities, have a negative $\beta_{i}$.

As Deaton and Muellbauer (1980) pointed out, if individual prices are highly collinear, variation in the log price index $\ln [a(p)]$ decreases, making the identification of $\alpha_{0}$ difficult. They suggested assigning a value to $\alpha_{0}$ a priori. Banks et al. (1997) further argued that the lowest value of log expenditure placed an upper bound on $\alpha_{0}$. Here, we assign the parameter $\alpha_{0}$ to the largest integer just below the minimum level of $\ln m$. We also tested a grid of values for $\alpha_{0}$ and our results remained robust to different values assigned to $\alpha_{0}$. We also adopt the price scaling technique introduced by Ray (1983), who incorporated demographic characteristics into the original AIDS model in his research on the cost of children. The compensated price elasticity estimates from AIDS models are found using the standard Slutsky decomposition.

\subsection{RESULTS AND DISCUSSION}

The full parameter estimates, standard errors and p-values obtained from estimating the basic AIDS model and the AIDS model augmented with demographic characteristics, based on an unweighted sample from the SHS, are shown in Table 1.2. Flexible demand system models contain a large number of parameters; these results are reported primarily for completeness. Note that we do not report the parameter estimates from the year and province indicator variables since their effects are not our primary interest here. We do not report the parameter estimates on the demographic characteristics for the AIDS model augmented with household demographic characteristics shown on the right panel of Table 1.2, as there are a very large number of parameters in this model. The full results are available on request from the authors. 
Table 1.2 AIDS model estimates

\begin{tabular}{lrlllrrr}
\hline & \multicolumn{3}{c}{ AIDS model } & & \multicolumn{2}{c}{ Augmented AIDS model } \\
\cline { 2 - 5 } \cline { 7 - 8 } & Coef. & Std. err. & p-value & & Coef. & Std. err. & p-value \\
\hline$\alpha 1$ & -0.281 & 0.023 & $<0.001$ & & -0.194 & 0.063 & 0.002 \\
$\alpha 2$ & 0.519 & 0.036 & $<0.001$ & & 1.164 & 0.088 & $<0.001$ \\
$\alpha 3$ & 0.762 & 0.031 & $<0.001$ & & 0.030 & 0.064 & 0.642 \\
$\beta 1$ & 0.002 & 0.0004 & $<0.001$ & & 0.024 & 0.006 & $<0.001$ \\
$\beta 2$ & 0.104 & 0.001 & $<0.001$ & & 0.219 & 0.010 & $<0.001$ \\
$\beta 3$ & -0.107 & 0.001 & $<0.001$ & & -0.243 & 0.010 & $<0.001$ \\
$\gamma 11$ & -0.202 & 0.025 & $<0.001$ & & -0.230 & 0.069 & 0.001 \\
$\gamma 21$ & 0.280 & 0.028 & $<0.001$ & & 0.293 & 0.079 & $<0.001$ \\
$\gamma 31$ & -0.078 & 0.005 & $<0.001$ & & -0.063 & 0.013 & $<0.001$ \\
$\gamma 22$ & -0.457 & 0.033 & $<0.001$ & & -0.543 & 0.093 & $<0.001$ \\
$\gamma 32$ & 0.176 & 0.006 & $<0.001$ & & 0.249 & 0.019 & $<0.001$ \\
$\gamma 33$ & -0.098 & 0.005 & $<0.001$ & & -0.187 & 0.014 & $<0.001$ \\
Observations & 145,560 & & & & 145,560 & & \\
\hline
\end{tabular}

In Table 1.2 the $\alpha_{i}$ 's are estimated intercepts, $\beta_{i}$ 's estimated parameters on the income variable, and $\gamma_{i j}$ 's reflect the effect on changes in own price and other prices on expenditure share. Like other research on demand systems, we focus on estimated price and income elasticities.

In general, the estimated parameters in both models are precisely estimated, as the p-values are quite small. The key parameters of interest in demand system models are the $\gamma_{i j}$ 's which indicate the impact of changes in the price of good $j$ on the budget share of good $i$. In Table 1.2 these parameter estimates are all statistically different from zero at conventional significance levels. Note that the inclusion of the demographic variables has little effect on the sign and significance of the key parameter estimates of interest; the results are robust to these different model specifications. The results are also robust to the use of sample weights from the SHS.

We focus primarily on the estimates income and price elasticities, since these have the most straightforward economic interpretation. The estimated income and price elasticities are shown in Table 1.3. The left panel contains estimates from the basic AIDS model and the right panel the AIDS model augmented with demographic characteristics.

In Table 1.3 "Attendance" refers to consumer spending on attendance at live sporting events; "Exercise" refers to consumer spending on leisure time physical activity and exercise and "Lottery" refers to consumer spending on government sponsored lotteries, which includes sports betting. In each $3 \times 3$ cell, the diagonal elements are the estimated own price elasticities and the off-diagonal elements are the estimated cross price elasticities. 
Table 1.3 Estimated income and price elasticities

\begin{tabular}{|c|c|c|c|c|c|c|}
\hline & \multicolumn{3}{|c|}{ AIDS model } & \multicolumn{3}{|c|}{ Augmented AIDS model } \\
\hline & Attendance & Exercise & Lottery & Attendance & Exercise & Lottery \\
\hline $\begin{array}{l}\text { Expenditure } \\
\text { Elasticity }\end{array}$ & 1.023 & 1.287 & 0.801 & 0.971 & 1.253 & 0.834 \\
\hline \multicolumn{7}{|c|}{ Compensated own and cross price elasticities } \\
\hline Attendance & -2.902 & 3.159 & -0.257 & -3.185 & 3.263 & -0.078 \\
\hline Exercise & 0.875 & -1.699 & 0.824 & 0.906 & -2.036 & 1.130 \\
\hline Lottery & -0.048 & 0.560 & -0.512 & -0.016 & 0.769 & -0.753 \\
\hline \multicolumn{7}{|c|}{ Uncompensated own and cross price elasticities } \\
\hline Attendance & -3.005 & 2.787 & -0.805 & -3.283 & 2.909 & -0.598 \\
\hline Exercise & 0.745 & -2.167 & 0.135 & 0.770 & -2.492 & 0.459 \\
\hline Lottery & -0.129 & 0.269 & -0.940 & -0.100 & 0.466 & -1.199 \\
\hline
\end{tabular}

Estimates of the expenditure elasticity for good $j$ are shown on the first row; the first set of estimates in row $i$, column $j$ contains the uncompensated cross price elasticity of expenditure category $i$ with respect to the changes in the price of good $j$. These uncompensated price elasticity estimates hold income and other prices constant, but allow utility to change with the price changes as consumers adjust their consumption bundle. The second set of estimates contains the "Hicksian" compensated price elasticity estimates that hold utility constant.

The uncompensated and compensated own price elasticities are uniformly negative, as predicted by standard consumer theory. As the price of each good or service goes up, consumer spending on that good or service falls, other things equal. Attendance at live sporting events has the highest price elasticity, and the estimated price elasticity on sports betting is relatively price inelastic.

The uncompensated and compensated estimated cross price elasticity between the price of sports betting and spending on live attendance at sporting events is negative; these goods are complements, and as the price of sports betting decreases, demand for both sports betting and live attendance at sporting events increases, other things equal. The opposite estimated cross price elasticity, between the price of attending live game sporting events and spending on lotteries and sports betting, is also negative. This provides additional support for the idea that these two types of consumer spending are complements.

This estimate has important implications. States and provinces across North America have recently been pushing for increased legal access to sports betting, especially in Canada, where the federal government has 
considered legalizing betting on individual sporting events. Sports leagues have generally opposed this proposed change, claiming that their revenues will be harmed by expanding access to legal betting. This estimated crossprice elasticity suggests that sports betting and spending on live attendance in Canada are complements. To the extent that increased legal opportunities to bet on sports reduces the price of betting on sports, these results predict that consumer spending on live game attendance will actually increase, contrary to the claims made by sports leagues.

The uncompensated and compensated estimated cross price elasticity between the price of sports betting and spending on participation in leisure time physical activity is positive; these goods are substitutes, and as the price of sports betting decreases, demand for participation in leisure time physical activity and exercise decreases, other things equal. The same relationship exists between the price of attending live sporting events and participating in physical activity: these are also substitutes.

These estimates also have important implications. If expanding legal access to sports betting reduces the price of sports betting, this will likely lead to a decrease in consumer demand for participation in leisure time physical activity and exercise. Increasing legal access to sports betting will tend to make Canadians more sedentary and less physically active. Since participation in physical activity and exercise has been shown to produce health benefits (Humphreys et al., 2014), expanding legal access to sports betting may have an unintended consequence of making Canadians less healthy, which may lead to increased national spending on health care.

\subsection{CONCLUSIONS}

This chapter develops evidence that spending on government sponsored lotteries, which encompasses sports betting in Canada, and spending on attendance at live sporting events are complements. When the price of one of these goods decreases, consumer spending on both increases. This relationship suggests that increasing access to legal sports betting, which can be interpreted as an increase in the supply of sports betting opportunities, should decrease the price of sports betting, and increase consumer spending on both sports betting and attendance at live sporting events. This evidence contradicts the claims made by professional sports leagues and the NCAA when opposing the expansion of legal sports betting in both Canada and the United States. If these results can be applied to proposed increases in access to legal sports betting in North America, professional and intercollegiate athletic teams and leagues in both countries could 
expect to see an increase in their revenues following the expansion of legal sports betting opportunities.

Sports teams and leagues have also raised the issue that increased access to legal sports betting will damage the public's perception of the legitimacy of the games sponsored by these leagues, by increasing the incentive for gamblers to influence the outcomes of the games by fixing games or matches. Existing evidence suggests that a significant amount of illegal sports betting already takes place in North America, and gamblers have access to on-line bookmakers. The presence of these alternatives would seem to already provide an incentive for gamblers to fix games or matches. Also Forrest and Simmons (2003) pointed out that the presence of legal sports betting opportunities actually allows law enforcement officials and sports leagues to detect match fixing more easily than would be possible in the absence of legal sports betting opportunities; after all, bookmakers stand to lose money when game or match outcomes are fixed by gamblers. These factors also argue against the claims made by sports teams and leagues when arguing against the expansion of legal sports betting opportunities.

The chapter also contains interesting evidence about a negative consequence of expanding legal opportunities to bet on sports as well as expanding opportunities to attend live sporting events. The results from the AIDS models suggest that household spending on leisure time physical activity is a substitute for spending on both government sponsored lotteries/sports betting and spending on attendance at live sporting events. As the price of sports betting and the price of attendance at live sporting events declines, demand for participation in physical activity and exercise also declines, as proxied by household spending on fees (including membership and single usage fees) and dues for sports activities, sports and recreation facilities, and health clubs. Reduced participation in physical activity and exercise can have adverse effects on both health outcomes and worker productivity, suggesting that expanding access to sports betting or live sporting events may have negative consequences on the health of individual Canadians and on the Canadian economy.

The results presented here require some caveats. The empirical results come from a sample of Canadian households that reported a positive level of spending on at least one of the three goods and services analyzed here. An expansion of access to legal sports betting could also have an effect on the spending of consumers who did not purchase any of these three goods or services. The behavior of these consumers could differ systematically from the behavior of the households that make up the sample analyzed here. We have used the price of purchasing a lottery ticket as the price of government sponsored lotteries and sports betting, which was either $\$ 1$ or 
\$2 throughout the sample period. The effective price of lottery gambling and sports betting can also depend on the expected return from these activities, which depend on the odds of winning, the size of the prizes and, in the case of sports betting, the over-round on the posted odds on various game outcomes. Although the own price elasticity estimates are negative and significant, the simple price measure for government sponsored lotteries and sports betting used here may not fully capture the prices faced by consumers making decisions to participate in sports betting.

\section{NOTE}

* We thank Irene Wong for her kind help in the University of Alberta Research Data Centre.

\section{REFERENCES}

Banks, J., Blundell, R., and Lewbel, A. 1997. Quadratic Engel curves and consumer demand. Review of Economics and Statistics, 79(4): 527-539.

Blow, L., Lechene, V., and Levell, P. 2012. Using the CE to model household demand. In Improving the Measurement of Consumer Expenditures, NBER Chapters, National Bureau of Economic Research.

Chang, D. and Serletis, A. 2014. The demand for gasoline: Evidence from household survey data. Journal of Applied Econometrics, 29(2): 291-313.

Deaton, A. and Muellbauer, J. 1980. An almost ideal demand system. The American Economic Review, 70(3): 312-326.

Forrest, D. and Pérez, L. 2011. Football pools and lotteries: Substitute roads to riches? Applied Economics Letters, 18(13): 1253-1257.

Forrest, D. and Simmons, R. 2003. Sport and gambling. Oxford Review of Economic Policy, 19(4): 598-611.

García, J., Pérez, L., and Rodríguez, P. 2008. Football pool sales: How important is a football club in the top division? International Journal of Sport Finance, 3(3): $167-176$.

García, J. and Rodríguez, P. 2007. The demand for football pools in Spain: The role of price, prizes, and the composition of the coupon. Journal of Sports Economics, 8(4): 335-354.

Gebreegziabher, Z., Mekonnen, A., Kassie, M., and Köhlin, G. 2012. Urban energy transition and technology adoption: The case of Tigrai, northern Ethiopia. Energy Economics, 34(2): 410-418.

Guta, D.D. 2012. Application of an almost ideal demand system (AIDS) to Ethiopian rural residential energy use: Panel data evidence. Energy Policy, 50: $528-539$.

Humphreys, B.R., McLeod, L., and Ruseski, J.E. 2014. Physical activity and health outcomes: Evidence from Canada. Health Economics, 23(1): 33-54.

Koohi-Kamali, F. 2013. Estimation of equivalence scales under convertible rationing. Review of Income and Wealth, 59(1): 113-132. 
Mangion, M.-L., Cooper, C., Cortes-Jimenez, I., and Durbarry, R. 2012. Measuring the effect of subsidization on tourism demand and destination competitiveness through the AIDS model: An evidence-based approach to tourism policymaking. Tourism Economics, 18(6): 1251-1272.

Ray, R. 1983. Measuring the costs of children: An alternative approach. Journal of Public Economics, 22(1): 89-102.

Sauer, R.D. 2001. The political economy of gambling regulation. Managerial and Decision Economics, 22(1-3): 5-15.

Simmons, R. 2007. Prohibition of gambling. In Meadowcroft, J. (ed.), Prohibitions (Readings in Economics). Institute of Economic Affairs.

Strumpf, K. 2003. Illegal sports bookmakers. University of North Carolina Chapel Hill Working Paper. 